\title{
Obesity in Children with Acute Promyelocytic Leukemia: What is its Incidence and Prognostic Significance?
}

Kathryn Laurie ${ }^{1}$, Paul Lee ${ }^{2}$, Alfred Rademaker ${ }^{3}$, Todd Alonzo ${ }^{4}$, Yi-Cheng Wang ${ }^{5}$, Bayard Powell $^{6}$, Diana $\mathrm{Wu}^{7}$, Richard Larson ${ }^{8}$, John Gregory ${ }^{9}$, Matthew Kutny ${ }^{10}$, Nobuko Hijiya ${ }^{11}$, and James Feusner ${ }^{12}$

${ }^{1}$ Goryeb Children's Hospital

${ }^{2}$ AbbVie Inc

${ }^{3}$ Northwestern University Feinberg School of Medicine

${ }^{4}$ University of Southern California

${ }^{5}$ Childrenś Oncology Group

${ }^{6}$ Wake Forest Baptist Comprehensive Cancer Center

${ }^{7}$ St Jude Children's Research Hospital

${ }^{8}$ University of Chicago

${ }^{9}$ Morristown Memorial Hospital

${ }^{10}$ University of Alabama at Birmingham

${ }^{11}$ Columbia University

${ }^{12}$ UCSF Benioff Children's Hospital Oakland

July 28, 2021

\begin{abstract}
Objective: To compare outcomes data of obese and non-obese pediatric patients with acute promyelocytic leukemia from the Cancer and Leukemia Group B trial C9710 and the Children's Oncology Group trial AAML0631. Methods: Data including demographics, adverse events, overall survival and event free survival was analyzed, with a focus on mortality in obese patients. Results: The incidence of obesity was $34 \%$ on C9710 and $35 \%$ on AAML0631. There was significantly lower overall survival in the obese population on AAML0631. Thirteen patients died during therapy or in follow up; seven of these occurred during induction. Conclusion: The incidence of obesity is higher in patients with APL compared to the general population. The presence and degree of obesity can influence OS on the most current treatment regimen. This implies the need for close management of obese patients at diagnosis as well as reinforces the need for further research on obesity driven APL
\end{abstract}

\section{Hosted file}

APL_obesity_Manuscript.docx available at https://authorea.com/users/427974/articles/532024obesity-in-children-with-acute-promyelocytic-leukemia-what-is-its-incidence-andprognostic-significance

\section{Hosted file}

Table1_PopulationCharacteristics.docx available at https://authorea.com/users/427974/ articles/532024-obesity-in-children-with-acute-promyelocytic-leukemia-what-is-itsincidence-and-prognostic-significance

\section{Hosted file}


Table2_AdverseEvents.docx available at https://authorea.com/users/427974/articles/532024obesity-in-children-with-acute-promyelocytic-leukemia-what-is-its-incidence-andprognostic-significance

\section{Hosted file}

Table3_MultivariableAnalysis.docx available at https://authorea.com/users/427974/articles/ 532024-obesity-in-children-with-acute-promyelocytic-leukemia-what-is-its-incidence-andprognostic-significance

\section{Hosted file}

Table4_PediatricDeaths.docx available at https://authorea.com/users/427974/articles/532024obesity-in-children-with-acute-promyelocytic-leukemia-what-is-its-incidence-andprognostic-significance

Figure 1 C9710 Kaplan-Meier Event Free and Overall Survival

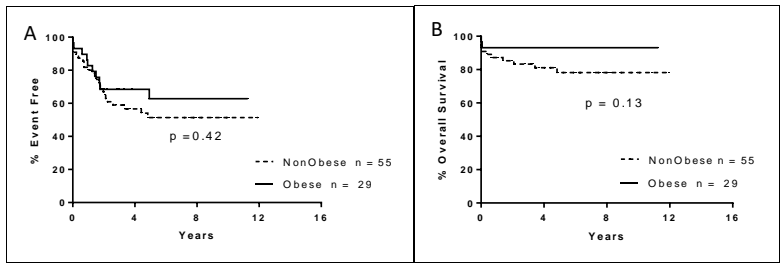


Figure 2 AAML0631 Kaplan-Meier Event Free and Overall Survival

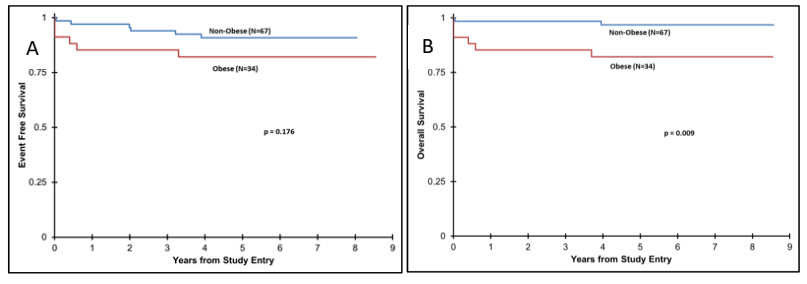

